\title{
Analisis Hukum Kekekalan Momentum Model Tumbukan Kelereng dengan Gantungan Ganda menggunakan Analisis Video Tracker
}

\author{
1Setya Utari, ${ }^{2}$ Eka Cahya Prima \\ ${ }_{1}$ Program Studi Pendidikan Fisika, Fakultas Pendidikan Matematika dan IImu Pengetahuan Alam, \\ Universitas Pendidikan Indonesia, Bandung 40154, Indonesia \\ 2 Program Studi Pendidikan IPA, Fakultas Pendidikan Matematika dan IImu Pengetahuan Alam, \\ Universitas Pendidikan Indonesia, Bandung 40154, Indonesia. \\ e-mail: setiyautari@upi.edu; ekacahyaprima@upi.edu
}

\begin{abstract}
Abstrak
Pengajaran sains tidak hanya terfokus pada apa yang harus siswa ketahui, tetapi dengan tantang era saat ini pengajaran sains lebih menekankan pada mengajarkan bagaimana cara mengetahui. Dengan tantangan ini maka yang penting bagaimana pembelajaran sains memberikan fasilitas untuk melatihkan cara mendapatkan pengetahuan dan cara menggunakan pengetahuan untuk menyelesaikan masalah, cara-cara ini yang kita kenal sebagai kompetensi literasi saintifik. Artikel ini memberikan gambaran tentang cara-cara membangun konsep Impuls dan momentum serta menggunakan teknologi untuk mendapatkan data yang berkualitas pada eksperimen tumbukan menggunakan analisis video tracker. Hasil pengujian menunjukkan analisis video tracker dengan menggunakan kit model tumbukan kelereng dengan gantungan ganda ini diperoleh eror yang cukup baik sebesar 0,01. Untuk model tumbukan lenting sempurna diperoleh nilai koefisien restitusi 1,01 , model tumbukan lenting sebagian dengan nilai koefisien restitusi $e=0,64$, dan model tumbukan tidak lenting dengan nilai koefisien restitusi $\mathrm{e}=0,001$. Kit pembelajaran ini merupakan terobosan terbaru untuk menguji hukum kekekalan momentum yang sangat cocok untuk pembelajaran fisika di SMP dan SMA dengan pemasangan yang mudah, sederhana, serta menghasilkan kontak pusat massa yang sangat baik.
\end{abstract}

Kata Kunci: kapasitansi; permitivitas relative; crude oil; IDCS.

\section{Analysis of Momentum Conservation Law on Marble Collisions with Double Hanger Model using Tracker Video Analysis}

\begin{abstract}
Nowadays, teaching science is not only focused on what students need to know; science teaching emphasizes the way of teaching about how to identify the things. By understanding this challenge, science learning should facilitate to train how to get knowledge and how to use knowledge to solve the problems, these ways we know as scientific literacy. This article overviews about the ways to construct Impulse and momentum concepts and how to use the technology to obtain useful quality data during collision experiments analyzed using Tracker Video Analisis. The results showed that the video tracker analysis using a double hanger model collision kit has successfully obtained a small error about 0.01 . For the perfect elastic collision model, the value of the experimental restitution coefficient is about 1.01, the partial elastic collision model has the value of the restitution coefficient $e=0.64$, and the inelastic collision model showed restitution coefficient $e=0.001$. This experiment kit is the latest breakthrough to test the momentum conservation law which is very suitable for learning physics in middle and high school with easy, simple installation and excellent mass center contact.
\end{abstract}

Keywords: expeiment kit, momentum conservation law, collision, tracker video analysis.

How to Cite: Utari, S., \& Prima, E. (2019). Analisis Hukum Kekekalan Momentum Model Tumbukan Kelereng dengan Gantungan Ganda menggunakan Analisis Video Tracker. Jurnal Pendidikan Fisika dan Keilmuan (JPFK), 5(2), 83-92. doi:http://dx.doi.org/10.25273/jpfk.v5i2.4145 


\section{PENDAHULUAN}

Proses pembelajaran yang saat ini berkembang di Indonesia masih menekankan pada hasil pembelajaran dan seringkali tidak memperhatikan proses untuk mendapatkan hasil tersebut. Indikator yang digunakan untuk menjadi ukuran keberhasilan suatu pembelajaran dilihat dari kemampuan siswa mengerjakan soalsoal ulangan, namun cenderung mengabaikan bagaimana proses pembelajaran berlangsung sebagai upaya membangun konsep dan pemahaman pada siswa (Karim dkk., 2017). Hal tersebut menjadi salah satu permasalahan yang muncul dalam pendidikan di Indonesia dewasa ini.

Sains merupakan bidang keilmuan yang empiris dengan menyertakan berbagai konsep yang membutuhkan kemampuan berpikir yang tinggi. Seringkali siswa mengalami kesulitan dalam mempelajari sains dikarenakan kurang efektifnya metode ataupun media pembelajaran yang digunakan sehingga guru dan siswa mengalami kesalahpahaman (Utari dkk., 2015). Pada dasarnya setiap siswa mempunyai kemampuan untuk belajar namun tidak semua siswa memiliki kapabilitas dan cara yang sama untuk belajar, sehingga hasil belajar pada setiap anak akan berbeda dengan metode yang sama. Oleh karena itu, dibutuhkan sebuah metode atau media pembelajaran yang dapat diterapkan se-efektif mungkin untuk semua siswa agar mereka dapat mengoptimalkan kemampuan berpikir mereka dalam memahami konsep sains.

Pemahaman konsep sangatlah penting dalam pembelajaran sains. Namun permasalahan yang terjadi dalam bidang pendidikan menyebabkan pembelajaran sains terfokus pada menghafal rumus atau metode untuk mengerjakan soal dan mengabaikan pemahaman konsep sehingga seringkali terjadi miskonsepsi dalam belajar sains (Fajarini dkk., 2018).

Sebagaimana pesatnya perkembangan teknologi atau modernisasi di dunia, seluruh aspek dalam kehidupan secara langsung ataupun tidak langsung turut mengalami integrasi dengan teknologi tidak terkecuali pendidikan. Dalam dunia pendidikan teknologi turut terintegrasi hampir dalam seluruh sistem dalam pendidikan seperti administrasi hingga media pembelajaran sederhana (Prima dkk., 2016). Pelaku-pelaku pendidikan terutama guru dituntut untuk dapat lebih kreatif dalam memanfaatkan kemajuan teknologi untuk meningkatkan kualitas pembelajaran terutama dalam bidang sains. Sains memiliki banyak sekali aspek yang abstrak dan sulit untuk di visualisasikan ke dalam bentuk pemikiran yang sederhana karena berisikan banyak teori, hukum, dan fakta yang harus dipahami dengan kemampuan berpikir tinggi secara saintifik. Teknologi dengan segala kelebihan dan kemampuannya dalam menjadi alat dan media mengakibatkan pesatnya perkembangan metode pembelajaran maupun media pembelajaran yang mendasarkan teknologi untuk menutupi kekurangan-kekurangan dalam pembelajaran sains konvensional.

Salah satu penerapan teknologi dalam pembelajaran sains adalah pembelajaran berbasis sains, teknologi, engineering, dan matematika (STEM) (Maulidah \& Prima, 2018). Dalam STEM siswa dituntut untuk belajar dengan teknologi, sekaligus aktif terlibat dalam praktek dan berpikir secara lebih saintifik serta bergelut dengan angka-angka (Yasin dkk., 2018). Siswa terlibat dalam kegiatan-kegiatan penyelidikan ilmiah yang tertanam dalam desain penyelesaian masalah dengan mengembangkan sebuah solusi yang berbasis sains dan teknologi. Dalam praktiknya, siswa dapat berpartisipasi aktif dalam kegiatankegiatan yang memicu mereka untuk dapat berpikir dan bertindak secara lebih

Jurnal Pendidikan Fisika dan Keilmuan (JPFK), Vol. 5, No. 2, September 2019, 83-92. 
relevan dan konsep-konsep yang abstrak dapat diterapkan dalam kegiatankegiatan yang menyenangkan. Dengan begitu, STEM diharapkan dapat menjadi solusi dalam mengatasi masalah-masalah untuk melampaui keterbatasan dalam pembelajaran sains.

Salah satu masalah dalam pembelajaran sains, khususnya Fisika adalah dalam mempelajari konsep gerak. Konsep gerak yang dipelajari dalam Fisika sulit dibuktikan melalui suatu eksperimen sederhana dikelas (Tayubi, 2005). Salah satu materi yang sulit dibuktikan secara eksperimen adalah pada materi momentum (Karim dkk., 2016).

Momentum suatu benda didefinisikan sebagai ukuran kesulitan untuk menghentikan gerak suatu benda. Secara matematis momentum dinyatakan sebagai hasil kali antara massa dan kecepatan suatu benda. Jika pada suatu sistem gaya eksternal netto yang bekerja adalah nol maka nilai momentum total dari sistem adalah kekal (tetap konstan sepanjang waktu) sehingga laju perubahan momentum total adalah nol. Hasil ini dikenal sebagai hukum kekekalan momentum. Hukum kekekalan momentum ini kana berguna ketika mempersoalkan peristiwa tumbukan.

Ketika dua buah benda mengalami tumbukan, dua benda akan saling mendekat, berinteraksi dengan kuat, dan saling menjauh. Benda-benda saling berinteraksi dengan kuat hanya terjadi saat tumbukan berlangsung. Jika gaya eksternal memiliki nilai yang lebih kecil dibandingkan gaya interaksi selama tumbukan, maka gaya eksternal tersebut dapat diabaikan. Ketika setelah peristiwa tumbukan energi kinetik total kedua benda adalah sama, maka tumbukan berlangsung secara elastik sempurna. Sedangkan jika energi kinetik setelah tumbukan lebih kecil dibandingkan energi kinetik sebelum tumbukan, maka tumbukan berlangsung tak elastik. Jika semua energi relatif hilang, dan bendabenda bergerak bersamaan dengan kecepatan yg sama maka tumbukan berlangsung tidak elastik sempurna.

Koefisien restitusi (e) merupakan ukuran keelastikan suatu tumbukan, didefinisikan sebagai rasio kelajuan saling menjauh relatif dan kelajuan saling mendekat relatif (Fruleux dkk., 2012). Untuk tumbukan elastik sempurna, e $=1$ sedangkan untuk tumbukan tak elastik $0<\mathrm{e}<1$ dan untuk tumbukan tak elastik sempurna $e=0$.

Hukum kekekalan momentum merupakan hukum yang sangat penting dalam fisika. Namun, konsep esensial dari momentum tersebut secara eksperimen sulit dibuktikan dalam pembelajaran dikelas. Hal tersebut karena untuk membuktikannya gerak dari benda pada suatu sistem harus dapat terukur, sedangkan sulit untuk menentukan metode yang tepat untuk mengukur gerak suatu benda secara tepat dengan tingkat presisi yang relatif rendah (Prima dkk., 2016).

Sejalan dengan perkembangan aplikasi teknologi dalam pendidikan dewasa ini, berbagai bahan dan metode belajar berbasis teknologi dapat digunakan untuk menunjang proses pembelajaran. Sehingga untuk dapat menganalisis gerak dan membuktikan hukum kekekalan momentum dapat dilakukan metode analisis dengan bantuan teknologi. Salah satu metode yang digunakan adalah metode analisis video menggunakan aplikasi Tracker Video Analisis (Wee dkk., 2012).

Tracker Video Analisis merupakan software yang dapat digunakan untuk membantu melakukan penelitian dalam hal kinematika secara komprehensif. VBL (Video Based Laboratory) merupakan teknologi video berbasis komputer yang dapat digunakan dalam pembelajaran sains. Melalui Tracker, yang dikembangkan untuk VBL dapat digunakan untuk menganalisis gejala fisis dalam bentuk video 
yang kemudian dapat merepresentasikan data kuantitatif maupun grafik secara simultan.

Dewasa ini, software Tracker banyak digunakan dalam pembelajaran, khususnya dalam menganalisis hal kinematika. Tracker dapat digunakan untuk menganalisis video tentang suatu kejadian baik yang terjadi secara alami maupun secara eksperimen, yang kemudian dapat diperoleh beberapa data besaran fisis yang berhubungan dengan posisi, kelajuan, kecepatan, percepatan, gaya, energi dan sebagainya. Dalam pembelajaran, tracker mulai digunakan untuk menganalisis gerak harmonik pada bandul, menganalisis gerak beraturan baik gerak lurus maupun gerak parabola. Namun aplikasi tracker untuk menganalisis konsep gerak dalam momentum belum dilakukan secara eksperimen dalam pembelajaran. Dalam artikel ini akan dibahas bagaimana membuktikan hukum kekekalan momentum secara eksperimen dengan menggunakan metode analisis video pada tracker.

\section{METODE PENELITIAN}

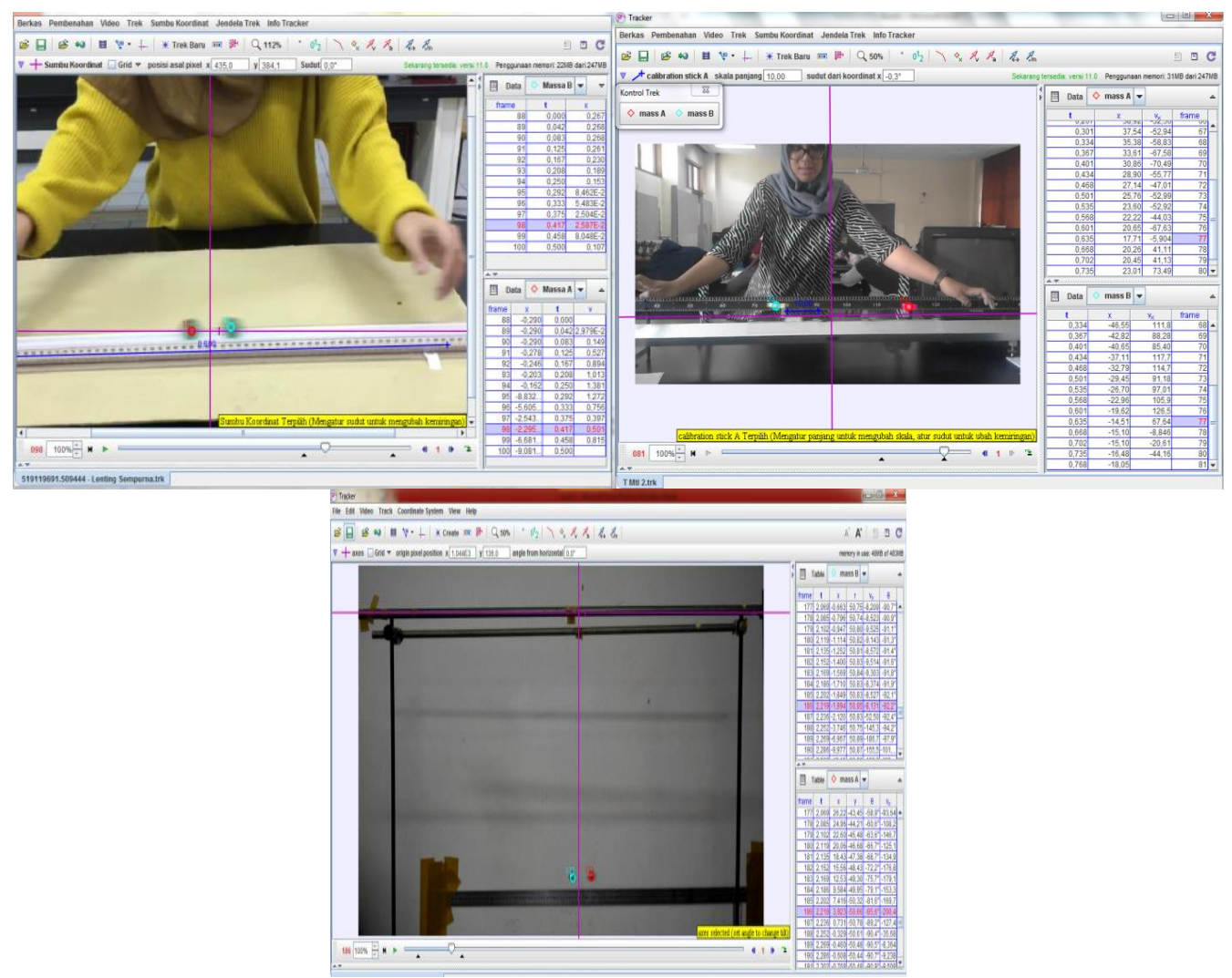

Gambar 1. Pengembangan eksperimen momentum dengan model tumbukan kelereng menggelinding (kiri atas), model tumbukan bantalan udara (kanan atas), model tumbukan kelereng dengan gantungan ganda (bawah)

Pada penelitian ini, sebagaimana terlihat pada Gambar 1, model tumbukan kelereng dengan gantungan ganda merupakan hasil pengembangan dari beberapa model tumbukan sebelumnya yaitu model tumbukan kelereng menggelinding dengan eror $53 \%$. Eror tersebut karena faktor putaran yang tidak bisa teridentifikasi oleh Tracker. Kemudian model diperbaiki dengan mengembangkan model 
tumbukan bantalan udara yang menghasilkan eror $13 \%$. Model tersebut diperbaiki dengan mengembangkan model tumbukan kelereng dengan gantungan ganda yang mampu meminimalisir efek putaran kelereng yang terjadi selama tumbukan. Model tumbukan ini menggunakan 2 buah kelereng dengan ukuran diamter 1,462 $\mathrm{cm}$ yang diberikan warna biru dan merah. Kelereng memiliki massa 16,60 gram. Warna tersebut dibedakan dengan tujuan agar mudah di-track menggunakan software Tracker. Kelereng digantung dengan panjang tali $30 \mathrm{~cm}$, dan sudut kedua buah tali membentuk 17o. Tali dibuat sedemkian rupa sehingga sejajar dari posisi paling bawah hingga atas. 4 buah statip digunakan dalam pembuatan model tersebut. Dua buah tali digantung dengan tujuan menghilangkan dampak putaran kelereng yang terjadi pasca tumbukan.

Pada eksperimen untuk membuktikan hukum kekekalan momentum dilakukan dengan menganalisis tumbukan yang terjadi pada dua bandul. Bandul yang digunakan diikat menggunakan seutas tali yang tipis dan diikatkan seperti dijelaskan pada Gambar 2, hal tersebut bertujuan untuk mengurangi rotasi pada bandul saat bergerak. Selanjutnya jarak antar bandul haruslah sama dengan jarak antara kedua titik pusat massa bandul, sehingga ketika mengikatkan tali pada statif jarak antar ikatan benang sama dengan jarak antar titik pusat massa kedua bandul.
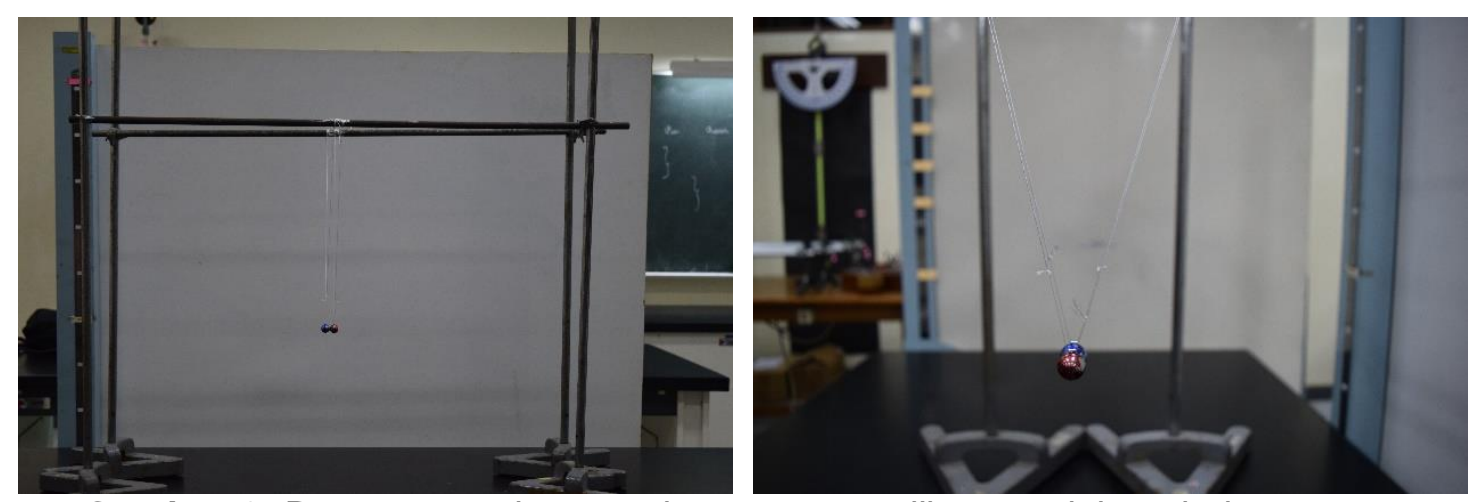

Gambar 2. Rancangan alat percobaan menampilkan model tumbukan gantungan ganda dengan tampak pinggir (kiri) dan tampak depan (kanan).

Berkaitan dengan prosedur percobaan menggunakan Analisis Video Tracker, Tracker bertujuan untuk menyelidiki kecepatan benda sesaat sebelum dan sesudah tabrakan. Dengan mengukur kecepatan sesaat dengan asumsi bahwa gesekan dan gerakan rotasi dapat diabaikan. Langkah percobaan diikuti dengan menyiapkan dua benda yang akan ditumbukan. Dapat diasumsikan bahwa tingkat kekerasan permukaan kelereng akan mempengaruhi tingkat kesempurnaan tumbukan elastis. Dalam penelitian ini akan diberikan contoh tiga jenis tumbukan baik tabrakan lenting, tabrakan sebagian, dan tabrakan tak lenting. Selain itu, perekaman video kualitas tinggi harus diatur sedemikian rupa di depan objek menggunakan penyangga yang stabil. Bidang pandang harus mencakup semua gerakan objek. Selain itu, perlu diperhatikan bahwa warna objek harus cukup jelas dibandingkan warna latar belakang sehingga program Tracker dapat mengikuti gerakan objek secara detail. Siswa dapat menggunakan penggaris atau dua titik yang ditentukan sebagai acuan kalibrasi untuk kalibrasi panjang dalam program Tracker. Setelah merekam video, siswa dapat menginstal program yang diunduh program dari https://physlets.org/tracker. Video dipasang dan dianalisis melalui 
program itu. Penting untuk diperhatikan bahwa sumbu koordinat harus diposisikan untuk menentukan koordinat posisi objek. Seorang guru harus meminta siswa untuk menyesuaikan kemiringan sumbu baik secara vertikal maupun horizontal. Dalam program ini, video ini akan dianalisis menggunakan ratusan frame hasil rekaman. Oleh karenanya, frame harus didefinisikan dengan baik yang mencakup sebelum dan sesudah tabrakan. Kalibrasi juga diatur dengan memperhatikan durasi video. Setelah itu, siswa perlu mengarahkan pada objek dan melakukan autotracking pada objek yang bergerak. Mereka harus menyesuaikan area objek dalam fitur itu untuk menentukan seberapa akurat objek yang akan dilacak. Semakin luas area, semakin akurat dan semakin lama autotracking, semakin baik hasilnya. Setelah autotracking, program akan menampilkan grafik dari objek yang bergerak. Beberapa parameter pada sumbu $x$ dan y dapat dilihat dalam program ini.

Ketika kedua bandul bertumbukan, frame yang menunjukan titik sebelum dan sesudah tumbukan yang kemudian akan dianalisis menggunakan analisis regresi linear. Pada frame tersebut dihitung nilai kecepatan sesaat sebelum dan sesudah tumbukan dengan persamaan kecepatan: $V_{x}=\frac{\Delta X}{\Delta t}$.

Dimana:

$V_{x} \quad=$ kecepatan benda pada komponen $\mathrm{x} \quad(\mathrm{m} / \mathrm{s})$

$\Delta X \quad=$ selisih kedua titik sesaat sebelum atau sesaat sesudah tumbukan $(\mathrm{m})$

$\Delta t \quad=$ selisih waktu (s)

Pada kasus ini bandul bergerak membentuk lintasan parabola, sehingga memiliki komponen kecepatan di sumbu vertikal (y) dan sumbu horizontal (x). Jika kita meninjau kembali hukum kekekalan momentum, maka dalam kasus ini:

$P=\sum_{i}^{n} m_{i} V_{i}=\sum_{i} m_{i}\left(V_{x}+V_{y}\right)=$ konstan

sehingga dapat dinyatakan

$P=\sum_{i}^{n} m_{i} V_{x}=$ konstan dan $P=$

$\sum_{i}^{n} m_{i} V_{y}=$ konstan 


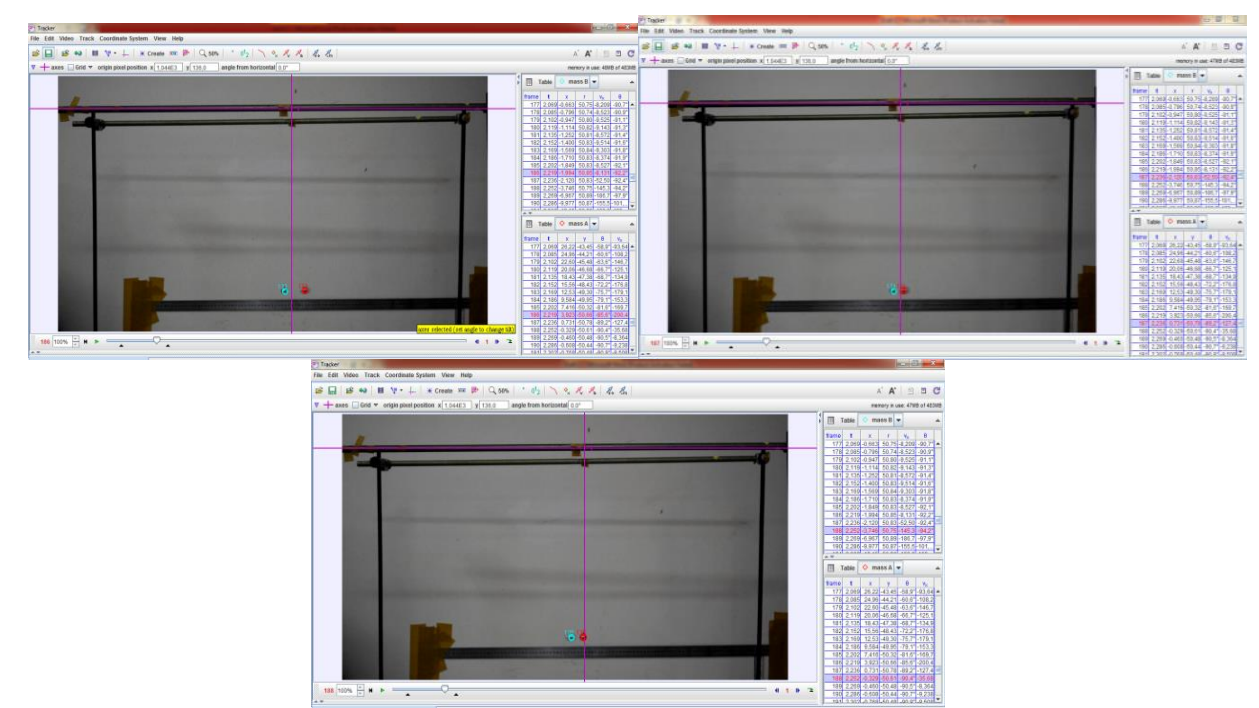

Gambar 3. Contoh analisis tumbukan lenting sempurna menggunakan metode analisis video Tracker. Frame sebelum tumbukan (kiri atas), frame ketika tumbukan (kanan atas), frame setelah tumbukan (bawah)

Tabel 1. Data tumbukan lenting sempurna

\begin{tabular}{lllllllll}
\hline Frame & & $\mathrm{Xa}(\mathrm{cm})$ & $\mathrm{Xb}(\mathrm{cm})$ & $\mathrm{t}(\mathrm{s})$ & $\mathrm{Va}(\mathrm{cm} / \mathrm{s})$ & $\mathrm{Vb}(\mathrm{cm} / \mathrm{s})$ & e & \multirow{2}{*}{ Error $(\%)$} \\
\hline 186 & $\mathrm{BC}$ & 3,923 & $-1,994$ & 2,219 & \multirow{2}{*}{$-191,33$} & $-7,54$ & & \\
187 & $187-186$ & 0,731 & $-2,120$ & 2,236 & & & \multirow{2}{*}{01,01} & 0,51 \\
188 & $\mathrm{AC}$ & $-0,329$ & $-3,746$ & 2,252 & $-7,88$ & $-193,04$ & & \\
189 & $189-188$ & $-0,460$ & $-6,967$ & 2,269 & & & & \\
\hline
\end{tabular}

Dimana:

$\mathrm{BC}=$ Before Collision / Sebelum Tumbukan, $\mathrm{AC}=$ After Collision / Setelah Tumbukan

$\mathrm{x}_{\mathrm{a}}=$ Posisi benda a terhadap titik $c$ di $\mathrm{sb} \mathrm{x}, \mathrm{x}_{\mathrm{b}}=$ Posisi benda $\mathrm{b}$ terhadap $\mathrm{c}$ di $\mathrm{sb} \mathrm{x}$

$\mathrm{t}=$ Waktu, $\mathrm{Va}=$ Kecepatan pada sumbu $\mathrm{x}$ untuk benda $\mathrm{a}, \mathrm{Vb}=$ Kecepatan pada sumbu $x$ untuk benda $b, e=$ Koefisien Restitusi

\section{HASIL DAN PEMBAHASAN}

Dengan menggunakan analisis video menggunakan aplikasi tracker diperoleh data berikut untuk ketiga jenis tumbukan. Untuk kasus tumbukan lenting sempurna sebagaimana ditunjukkan pada Tabel 1 dan Gambar 3, digunakan dua buah bandul yang identik material, massa, ukuran dan permukaan pantulnya. Koefisien resititusi ditentukan dengan persamaan sebagai berikut.

\section{Dengan}

$$
e=\frac{-\left(V_{b}^{\prime}-V_{a}^{\prime}\right)}{\left(V_{b}-V_{a}\right)},
$$

Vb' = Kecepatan pada sumbu $\mathrm{x}$ untuk benda $\mathrm{b}$ setelah tumbukan

Va' = Kecepatan pada sumbu $\mathrm{x}$ untuk benda a setelah tumbukan

$\%$ Err = Tingkat presisi / kesalahan

$$
\% \text { Err }=\frac{P-P^{\prime}}{P+P^{\prime}} \text {, dengan } P=m\left(V_{a}+V_{b}\right) \text { dan } P^{\prime}=m\left(V_{a}^{\prime}+V_{b}^{\prime}\right)
$$

$\mathrm{H}=$ selisih tumbukan akhir dan tumbukan awal $H=P^{\prime}-P$

Pada kasus tumbukan lenting sempurna, diperoleh 4 frame yang menunjukan titiktitik sesaat sebelum dan sesaat sesudah tumbukan. Pengambilan keempat frame ini karena titik saat tepat bertumbukan tidak dapat terdeteksi oleh aplikasi, 
meskipun resolusi video dan pengaturan dalam tracker sudah menggunakan ketelitian yang tinggi karena keterbatasan aplikasi ini maka titik saat tepat bertumbukan tidak dapat terdeteksi. Karena keterbatasan ketelitian ini lah yang menyebabkan adanya faktor kesalahan dalam pengukuran.

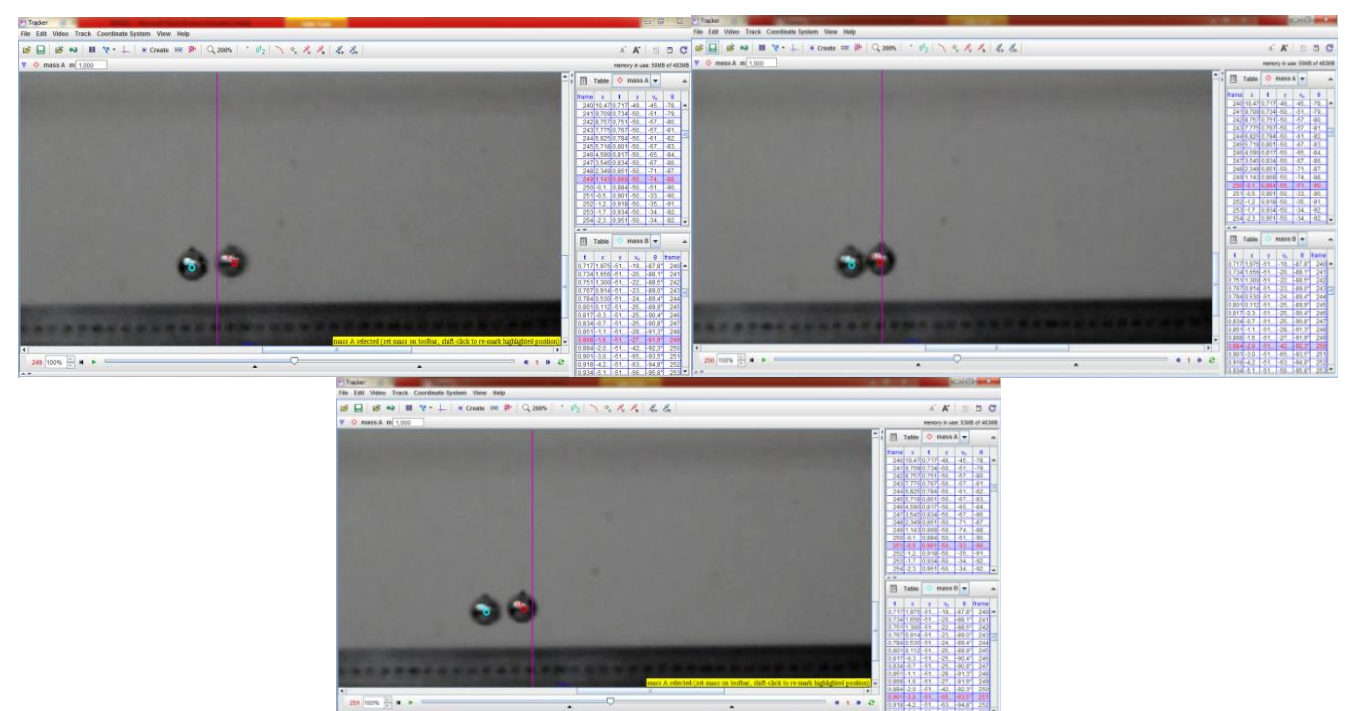

Gambar 4. Contoh analisis tumbukan lenting sebagian menggunakan metode analisis video Tracker. Frame sebelum tumbukan (kiri atas), frame ketika tumbukan (kanan atas), frame setelah tumbukan (bawah). Pada kelereng ditambahkan satu lembar selotip untuk menghasilkan model tumbukan lenting sebagian

Tabel 2. Data tumbukan lenting sebagian

\begin{tabular}{lllllllll}
\hline \multicolumn{2}{l}{ Frame } & $\mathrm{Xa}$ & $\mathrm{Xb}$ & $\mathrm{T}$ & $\mathrm{Va}$ & $\mathrm{Vb}$ & $\mathrm{e}$ & Eror (\%) \\
\hline 249 & $\mathrm{BC}$ & 1,143 & $-1,666$ & 0,868 & $-76,36$ & $-25,75$ & & \\
250 & $\mathrm{C}$ & $-0,131$ & $-2,095$ & 0,884 & & & 0,64 & 8,54 \\
& & & & & & &
\end{tabular}

Dimana:

$\mathrm{BC}=$ Before Collision / Sebelum Tumbukan, $\mathrm{AC}=$ After Collision / Setelah Tumbukan

$\mathrm{x}_{\mathrm{a}}=$ Posisi benda a terhadap titik $\mathrm{c}$ di $\mathrm{sb} \mathrm{x}, \mathrm{x}_{\mathrm{b}}=$ Posisi benda $\mathrm{b}$ terhadap $\mathrm{c}$ di $\mathrm{sb} \mathrm{x}$

$\mathrm{t}=$ Waktu, $\mathrm{Va}=$ Kecepatan pada sumbu $\mathrm{x}$ untuk benda $\mathrm{a}, \mathrm{Vb}=$ Kecepatan pada sumbu $x$ untuk benda $b, e=$ Koefisien Restitusi

Pada kasus tumbukan lenting sebagian sebagaimana terlihat pada Tabel 2 dan Gambar 4, digunakan dua buah bandul dengan massa dan ukuran yang sama namun divariasikan permukaan pantulnya dengan melapisi salah satu permukaan bandul menggunakan material lain, pada percobaan digunakan dua lapis selotip.

Berbeda dengan kasus pada tumbukan elastik sempurna, pada kasus tumbukan elastik sebagian diperoleh tiga titik yang menunjukan titik sesaat sebelum tumbukan, saat terjadi tumbukan dan sesaat setelah tumbukan.

Sedangkan untuk kasus tumbukan tidak lenting sama sekali sebagaimana terlihat pada Tabel 3 dan Gambar 5, kedua buah bola dipasang perekat, sehingga saat terjadi tumbukan keduanya akan menempel dan bergerak bersamaan. Agar memudahkan saat menganalisis menggunakan tracker digunakan pewarna yang berbeda pada kedua permukaan bola menggunakan cat akrilik. Seperti halnya 
tumbukan elastik sempurna, pada kasus tumbukan tak elastik sempurna juga menggunakan empat titik untuk menganalisis tumbukan yang terjadi pada kedua bandul.

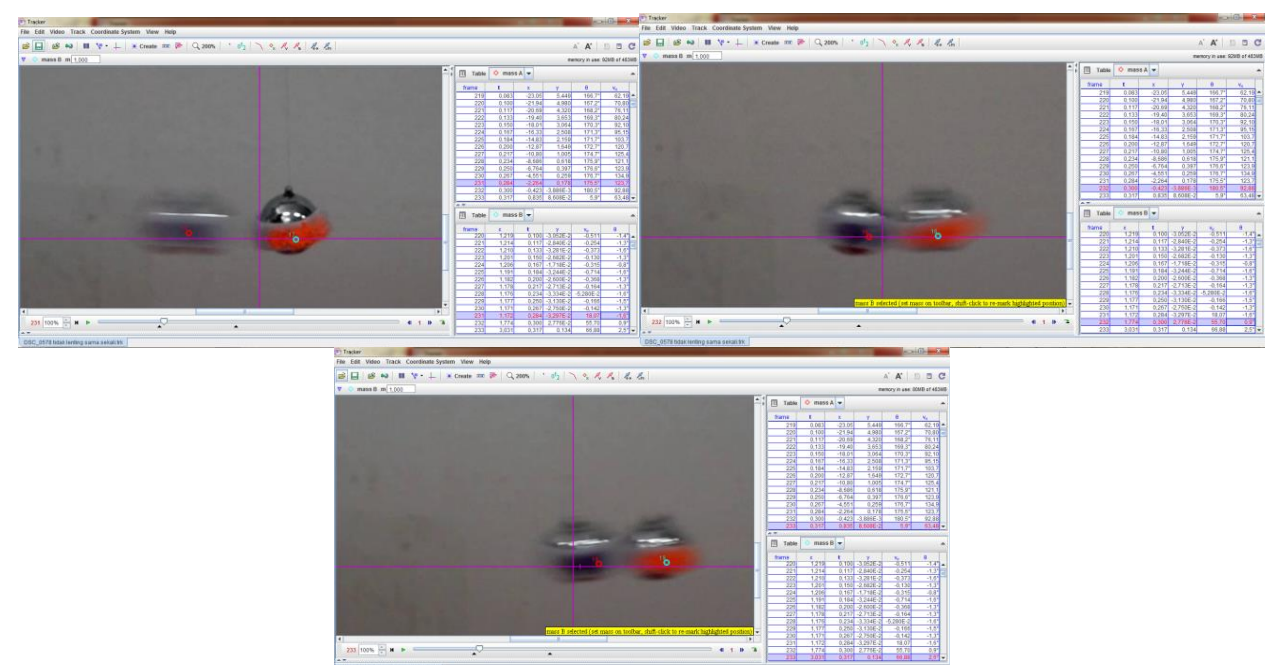

Gambar 5. Contoh analisis tumbukan tak lenting menggunakan metode analisis video Tracker. Frame sebelum tumbukan (kiri atas), frame ketika tumbukan (kanan atas), frame setelah tumbukan (bawah). Pada kelereng ditambahkan satu lembar double tip untuk menghasilkan model tumbukan tak lenting

Tabel 3. Data tumbukan tak lenting

\begin{tabular}{lllllllll}
\hline Frame & & $\mathrm{Xa}$ & $\mathrm{Xb}$ & $\mathrm{T}$ & $\mathrm{Va}$ & $\mathrm{Vb}$ & $\mathrm{e}$ & Eror (\%) \\
\hline 230 & $\mathrm{BC}$ & $-4,551$ & 1,171 & 0,267 & \multirow{2}{*}{137,047} & 0,058 & & \\
231 & $231-232$ & $-2,264$ & 1,172 & 0,284 & & & 0,001 & 4,73 \\
232 & AC & $-0,423$ & 1,774 & 0,300 & 75,400 & 75,323 & & \\
233 & $233-232$ & 0,835 & 3,031 & 0,317 & & & & \\
\hline
\end{tabular}

Dimana:

$\mathrm{BC}=$ Before Collision / Sebelum Tumbukan, $\mathrm{AC}=$ After Collision / Setelah Tumbukan

$\mathrm{xa}=$ Posisi benda a terhadap titik $\mathrm{c}$ di $\mathrm{sb} \mathrm{x}, \mathrm{x}_{\mathrm{b}}=$ Posisi benda $\mathrm{b}$ terhadap $\mathrm{c}$ di $\mathrm{sb} \mathrm{x}$

$\mathrm{t}=$ Waktu, $\mathrm{Va}=$ Kecepatan pada sumbu $\mathrm{x}$ untuk benda $\mathrm{a}, \mathrm{Vb}=$ Kecepatan pada sumbu $x$ untuk benda $b, e=$ Koefisien Restitusi

Dibandingkan dengan model tumbukan sebelumnya yaitu model tumbukan kelereng menggelinding yang menghasilkan eror 53\%. Eror tersebut karena faktor putaran yang tidak bisa teridentifikasi oleh Tracker sehingga nilainya tidak bisa memenuhi hukum kekekalan momentum. Selain itu, model model tumbukan bantalan udara komersial juga yang menghasilkan eror $13 \%$. Hal tersebut terjadi karena masih adanya dampak gesekan yang terjadi selama tumbukan. Model yang telah dikembangkan mampu memperbaiki kesalahan yang terjadi selama proses tumbukan. Pertama bahwa kondisi kelereng yang digantung akan mengurangi gesekan secara signifikan selama gerakan kelereng tersebut hingga terjadinya tumbukan. Kedua, penggunaan warna merah dan biru sangat membantu program Tracker untuk memastikan bahwa tumbukan terjadi baik secara lenting, lenting sebagian, maupun lenting sempurna. Data menunjukan bahwa 99,49\% hukum kekekalan momentum dapat dibuktikan melalui percobaan tumbukan lenting 
sempurna. Selain itu, data tumbukan lenting sebagian dan tak lenting sama sekali sama-sama mampu membuktikan $91,46 \%$ dan 95,27\% hukum kekekalan momentum. Model ini dapat dijadikan rujukan untuk pengembangan kit praktikum model tumbukan untuk membuktikan hukum kekekalan momentum di sekolah. Koefisien resititusi yang dihasilkan dalam penelitian ini sangat mendekati kondisi ideal untuk fenomena tumbukan. Untuk model tumbukan lenting sempurna diperoleh nilai koefisien restitusi 1,010, model tumbukan lenting sebagian dengan nilai koefisien restitusi $e=0,640$, dan model tumbukan tidak lenting dengan nilai koefisien restitusi $e=0,001$.

\section{KESIMPULAN}

Dengan menggunakan metode analisis video tumbukan pada bandul menggunakan aplikasi tracker, diperoleh data dengan eror lebih rendah dari model tumbukan bantalan udara komersial. Hasil pengujian model tumbukan kelereng dengan gantungan ganda mampu menghasilkan eror yang lebih kecil dari model komersial sebesar 0,51\%. Untuk model tumbukan lenting sempurna diperoleh nilai koefisien restitusi 1,010 , model tumbukan lenting sebagian dengan nilai koefisien restitusi $e=0,640$, dan model tumbukan tidak lenting dengan nilai koefisien restitusi $\mathrm{e}=0,001$.

\section{DAFTAR PUSTAKA}

Fajarini, F., Utari, S., \& Prima, E. (2018). Identification of students' misconception against global warming concept. International Conference on Mathematics and Science Education of Universitas Pendidikan Indonesia,

Fruleux, A., Kawai, R., \& Sekimoto, K. (2012). Momentum transfer in nonequilibrium steady states. Physical review letters, 108(16), 160601. https://doi.org/https://doi.org/10.1103/PhysRevLett.108.160601

Karim, S., Prima, E. C., Utari, S., Saepuzaman, D., \& Nugaha, M. G. (2017). Recostructing the physics teaching didactic based on marzano's learning dimension on training the scientific literacies. Journal of Physics: Conference Series,

Karim, S., Saepuzaman, D., \& Sriyansyah, S. (2016). The learning reconstruction of particle system and linear momentum conservation in introductory physics course. Journal of Physics: Conference Series,

Maulidah, S. S., \& Prima, E. C. (2018). Using Physics Education Technology as Virtual Laboratory in Learning Waves and Sounds. Journal of Science Learning, 1(3), 116-121. https://eric.ed.gov/?id=EJ1226300

Prima, E. C., Mawaddah, M., Winarno, N., \& Sriwulan, W. (2016). Kinematics investigations of cylinders rolling down a ramp using tracker. AIP Conference Proceedings,

Tayubi, Y. R. (2005). Identifikasi miskonsepsi pada konsep-konsep fisika menggunakan Certainty of Response Index (CRI). Mimbar Pendidikan, 3(24), 49.

Utari, S., Karim, S., Setiawan, A., Nugraha, M. G., Saepuzaman, D., \& Prima, E. C. (2015). Designing Science Learning for Training Students' Science Literacies at Junior High School Level. Int. Conf. on Mathematics, Science, and Education,

Wee, L. K., Chew, C., Goh, G. H., Tan, S., \& Lee, T. L. (2012). Using Tracker as a pedagogical tool for understanding projectile motion. Physics Education, 47(4), 448. https://iopscience.iop.org/article/10.1088/0031-9120/47/4/448

Yasin, A. I., Prima, E. C., \& Sholihin, H. (2018). Learning Electricity Using ArduinoAndroid Based Game to Improve STEM Literacy. Journal of Science Learning, 1(3), 77-94. https://eric.ed.gov/?id=EJ1226377 